\title{
細 \\ PEREMPUAN DAN TEKNOLOGI INFORMASI DALAM PERSPEKTIF CYBERFEMINIST
}

\author{
Suharnanik, M.Si \\ Program Studi Sosiologi Fakultas Ilmu Sosial dan Ilmu Politik \\ Universitas Wijaya Kusuma Surabaya (UWKS)
}

Email:nanikoye@gmail.com

\begin{abstract}
Abstrak
Penelitian ini menggunakan perspektif cyberfeminis yang membahas tentang wanita sebagai pengguna teknologi informasi. Perspektif yang digunakan ini berpusat pada perempuan yang penggunaan teknologi informasi dalam mencapai pemberdayaan perempuan. Penggunaan teknologi informasi mampu membuka jalan baru yang menyediakan peluang kerja dan kreativitas bagi perempuan dimana tidak ada seksisme, rasisme dan penindasan. Dengan berkembang kemampuan perempuan di bidang teknologi informasi akan menurunkan superioritas pria terhadap wanita. Topik diskusi ini adalah bagaimana perempuan dan teknologi dapat terganggu dan perubahan sosial apa yang akan terjadi. Sebanyak 8 wanita dilibatkan dalam penelitian ini, latar belakang mereka sebagai guru, dokter, pengusaha dan ibu rumah tangga. Hasil penelitian ini menunjukkan bahwa teknologi informasi memiliki dampak besar pada keberhasilan wanita dalam jual-beli on-line. Informasi tersebut bukan untuk mencari identitas baru di dunia on-line tetapi informasi tersebut digunakan untuk bertahan hidup di sektor ekonomi.
\end{abstract}

Kata Kunci : Wanita, Informasi, Cyberfeminist.

\begin{abstract}
This research uses cyberfeminist perspective to discuss about woman as user of information technology. Women-centered perspectives that advocate the use of information technology in achieving women's empowerment. The use of information technology is able to open new avenues that provide job opportunities and creativity for women where there is no sexism, racism and oppression. With the development of women's ability in the field of information technology will reduce the superiority of men to women. The topic of discussion will be on how women and technology can be interfered and what social changes will be occured. A total of 8 women involved in this study, background of the profession as a teacher, doctors, employers and housewives. The results of this study indicate that information technology has a major impact on the success of woman for buying and selling on-line. The information is not in order to seek a new identity in the on-line world but the information is used to survive in economi sector.
\end{abstract}

Key Word : Woman, Information, Cyberfeminist. 


\section{LATAR BELAKANG}

Belanja on-line telah menjadi bagian dari gaya hidup masyarakat terutama bagi masyarakat perkotaan. Kota Surabaya mendapat rangking pertama jumlah penduduknya yang mengakses teknologi untuk belanja on-line, hanya sepertiganya saja yang tidak melakukan belanja on-line. Data ${ }^{1}$ menunjukkan $71 \%$ penduduk Surabaya melakukan belanja on-line, kemudian Medan dengan 68\%, Jakarta dengan 66\%, Bodetabek (Bogor, Depok, Tangerang, Bekasi) dengan 65\%, Bandung dengan 63\%, Semarang dengan 59\% dan Makasar dengan 52\%. Selain itu, hasil evaluasi implementasi situs eGovernment menunjukkan bahwa Kota Surabaya jauh lebih baik dibanding Kota-kota lainnya. Hasil ini sama dengan evaluasi PeGi dari tahun 2012-2014 bahwa dalam pemeringkatan Situs Web eGovernment selama ini hanya didominasi oleh pemerintahan di pulau Jawa (Sitokdana, 2015). Artinya, data tersebut menunjukkan bahwa secara merata beberapa kota di Indonesia sudah melek dengan internet. Jakarta tidak lagi menjadi kota yang penduduknya melakukan interaksi dagang secara on-line tertinggi. Akan tetapi, Surabaya sebagai kota industri dan jasa memiliki potensi tinggi yang menjadi peluang perempuan dalam menggunakan teknologi informasi seperti internet.

Beberapa artikel menyebut media on-line belum menyentuh keseimbangan antara laki-laki dan perempuan dalam mengakses teknologi. ${ }^{2}$ Perempuan masih di bawah laki-laki secara jumlah, namun beberapa kendala seperti budaya perempuan yang mengalami technophobia dibandingkan laki-laki. ${ }^{3}$ Akibatnya, Political Blogging yang mempengaruhi makna gender itu sendiri dalam kultur budaya on-line. ${ }^{4}$ Dalam konteks ini, beberapa negara berkembang teknologi informasi mampu meningkatkan pemberdayaan perempuan secara ekonomi dan sosial..$^{5}$ Akhirnya, cyberfeminist menganggap bahwa ruang on-line mampu menciptakan ruang pembebasan bagi perempuan. ${ }^{6}$ Selain itu, penelitian cyberfeminist mampu mereduksi gender pada perempuan kulit berwarna yang dianggap miskin (Fernande, 2003). Berbeda dengan penelitian ini, lebih menitikberatkan pada penggunaan teknologi informasi bagi perempuan sebagai sarana jual beli on-line, kemudian peneliti menganalisanya dalam perspektif cyberfeminist. Sebagai sebuah gerakan kaum perempuan yang terhibridisasi dengan teknologi mampu menyuarakan dirinya sebagai pribadi yang diakui dan sejajar dengan laki-laki.

Teknologi informasi menjadi hal yang penting dalam menentukan pola perubahan sosial yang terjadi saat ini. Pergeseran perubahan sosial tersebut terjadi pula pada perempuan yang selama ini masih mengalami ketertinggalan dibandingkan dengan laki-laki. Kesenjangan dalam mengakses teknologi informasi terjadi di beberapa negara di

\footnotetext{
${ }^{1}$ Survey data tersebut dilakukan oleh google bekerjasama dengan Gfk, riset ini dilakukan untuk semua platform E-commerce dengan 1.000 responden selama dua bulan (detik.com, 15 agustus 2017).

2 Jianwei Hou. 2014. On Line stock trading: Do Demographics, Internet Usage, and Attiudes Matter?. Minnesota State University Mankato. Amerika Serikat.

${ }_{3}^{3}$ Martin Hilbert. 2011. Digital gender divide or technologically empowered women in developing countries? (A typical case of lies, damned lies, and statistics), (University of Southern California (USC); United Nations Economic Commission for Latin America and the Caribbean (ECLAC/CEPAL).

${ }^{4}$ Olena Gorosho dan Olena Zhigalina., 2011. "Political Blogging: at crossroads of Gender and cultural Online?" Gendered Transformation; Theory and Practices on Gender and Media. The University of Chicago Press. USA.

${ }^{5}$ Lal B. Suresh, 2011. Impact of Information and Communication Technologies on Women Empowerment in India, Jurnal, Department of Economics, Kakatiya University Warangal, Andhra Pradesh -506001, India. VOLUME 9 - NUMBER 4 -YEAR 2011. ISSN: 1690-4524

${ }^{6}$ Rosser, S. V. (2005). Through the Lenses of Feminist Theory: Focus on Women and Information Technology. Frontier , 26, 185.
} 
dunia, seperti dalam penelitiannya Hilbert dimana persentase laki-laki lebih tinggi dibandingkan dengan perempuan yang menggunakan internet di negara-negara maju seperti Australia, Republik Ceko, Hongaria, Israel, Selandia Baru, Singapura, Inggris Raya, sedangkan di negara Swedia lebih berimbang persentasenya dalam penggunaan $\mathrm{ICT}^{7}$ antara laki-laki dan perempuan. ${ }^{8}$ Surabaya, sebagai kota besar kedua setelah Jakarta, menempati urutan nomor satu dengan prosentase mencapai $71 \%$ penduduknya melakukan belanja on-line, kemudian disusul dengan Medan dengan 68\%, Jakarta dengan 66\%, Bodetabek (Bogor, Depok, Tangerang, Bekasi) dengan 65\%, Bandung dengan 63\%, Semarang dengan 59\% dan Makasar dengan 52\%. ${ }^{9}$ ICT (Hilbert) mampu meningkatkan pemberdayaan perempuan, dengan ICT perempuan dapat menjadi pengusaha yang mampu mengembangkan bisnisnya keseluruh dunia secara 24 jam sehari-hari tanpa batas ruang dan waktu. ${ }^{10}$ Dibeberapa Negara berkembang perempuan lebih mudah untuk dilatih ketrampilannya dalam bidang penguasaan komputer, yang didapatkan dari luar sistem pendidikan formal. ${ }^{11}$ Dari beberapa penelitian tersebut lebih menekankan pola perubahan, kesenjangan dalam akses, potensi perempuan dan peluang yang sama tapi belum maksimal dimanfaatkan oleh perempuan. Penelitian belum menyentuh pada penggunaan informasi bagi perempuan, meskipun disinggung beberapa kebergunaannya untuk peningkatan pemberdayaan ekonomi, namun belum menyentuh referensial teoritik yang terkait informasi dan hibridisasi perempuan dan teknologi. Penelitian ini memberikan sudut pandang yang berbeda dengan penelitian sebelumnya karena lebih menekankan pada studi referensi teori masyarakat informasional Manuel Castells tentang bagaimana penggunaan informasi bagi perempuan beserta konsep Cyberfeminist yang saling terkait dengan perempuan dan teknologi. Penelitian ini lebih menitik beratkan apakah informasi bagi perempuan sebagaimana konsep Castells yang lebih menekankan pada pencarian identitas diri atau yang lainnya?

\section{METODE}

Metode penelitian ini menggunakan studi kasus pada delapan perempuan yang aktif menggunakan informasi dan teknologi komputer dalam mendukung kegiatan jual beli on-line. Penelitian menggunakan pendekatan kualitatif yang lebih mengutamakan data-data yang berupa cerita dari hasil wawancara mendalam dengan informan yang dipilih. Selain itu, peneliti melakukan pengamatan, ikut serta dalam kegiatan kumpul bersama komunitas perempuan trading on-line. Dalam konteks ini, peneliti menghindari pembahasan kegiatan perdagangan yang lebih cenderung bidang ekonomi praktis yang tentunya secara kajian sosiologis tidak tepat. Akan tetapi, peneliti lebih fokus pada analisis kritis pada perempuan menggunakan teknologi informasi dalam perspektif cyberfeminist. Dengan mengacu

\footnotetext{
${ }^{7}$ ICT merupakan singkatan dari Information, communication and technology.

${ }^{8}$ Martin Hilbert, Digital gender divide or technologically empowered women in developing countries?

(A typical case of lies, damned lies, and statistics), (University of Southern California (USC); United Nations Economic

Commission for Latin America and the Caribbean (ECLAC/CEPAL) tahun 2011, hlm. 1-2

${ }_{9}^{9}$ Survey data tersebut dilakukan oleh google bekerjasama dengan Gfk, riset ini dilakukan untuk semua platform

E-commerce dengan 1.000 responden selama dua bulan (detik.com, 15 agustus 2017).

${ }^{10}$ Martin Hilbert. 2011. Digital gender divide or technologically empowered women in developing countries? (A typical case of lies, damned lies, and statistics), (University of Southern California (USC); United Nations Economic Commission for Latin America and the Caribbean (ECLAC/CEPAL). hlm. 2

${ }^{11}$ Nancy Hafkin and Nancy Taggart, Gender, Information Technology, and Developing Countries: An Analytic Study, (Academy for Educational Development (AED) For the Office of Women in Development Bureau for Global Programs, Field Support and Research United States Agency for International Development: June 2000), hlm. 3-4
} 
pada beberapa hasil studi penelitian terdahulu yang menunjukkan perlakuan tidak wajar pada perempuan dengan membedakan fasilitas dan kesempatan terhadap teknologi informasi, seperti laki-laki lebih diutamakan, kultur budaya technophobia, serta meragukan kemampuan perempuan.

Kota Surabaya menjadi pilihan tempat penelitian ini, karena tingkat penggunaan internet sebagai on-line shop di instagram tinggi. ${ }^{12}$ Selain itu, teknologi informasi yang menggunakan internet digunakan untuk mengetahui tentang seksualitas (Novandra, 2017) dan informasi kesehatan dalam menentukan keputusan untuk memilih perawatan dan pengobatan medis yang tepat (Aryaningsih, 2011). Beberapa pengusaha perempuan menggunakan e-commerce untuk penjualan serta mencari pemasok barang-barang yang murah (Fauzia, 2015).

Perspektif cyberfeminis dipilih dalam menganalisis studi kasus ini karena lebih tepat sasaran secara subyek dan kondisi perempuan dalam menggunakan teknologi. Seperti (Fernandez \& Wilding, 2002), menggunakan cyberfeminist karena dianggap relevan untuk menggambarkan situasi perempuan yang menggunakan teknologi di Amerika Serikat. Pemahaman berbeda dari Volkart, menyebutkan bahwa cyborg sebagai sebutan perempuan yang terhibridisasi dengan teknologi tidak sepenuhnya perempuan tersebut selalu menggunakan teknologi digital yang terbaru (Volkart, 2004). Kategori perempuan cyborg juga dapat digunakan pada perempuan yang menggunakan mesin teknologi yang lama, seperti: komputer dengan program lama, gadget yang masih $3 \mathrm{G}$ atau mesin jahit yang manual. Namun, pembandingnya adalah terletak pada kecepatan dan penggunaan mesin teknologi tersebut mampu membuat perempuan memiliki kekuatan dan ketahanan dalam menghadapi hidupnya. Biarpun demikian, bukan berarti penelitian ini mendukung sepenuhnya perspektif ini, justru celah dan kritik terhadap perspektif ini muncul dalam studi ini. Perempuan yang terhibridisasi dengan teknologi di anggap sebagai cyborg yang membangun keberdayaannya dalam kondisi kehidupan saat ini. Sebagai manusia cyborg, dalam pandangan cyberfeminis diharapkan berkontribusi untuk membentuk koalisi sesama perempuan dan menghasilkan kebijakan yang responsif terhadap perempuan.

\section{PEMBAHASAN}

Informasi merupakan sekumpulan data atau fakta yang diolah dengan cara tertentu sehingga mempunyai arti bagi penerima. ${ }^{13}$ Sedangkan menurut KKBI informasi merupakan pemberitauan kabar atau berita tentang sesuatu. ${ }^{14}$ Informasi menjadi perihal yang sangat penting bagi perempuan trader on-line, kebutuhan akan informasi bagi perempuan membutuhkan sebuah alat yang canggih dan modern seperti internet, laptop, gadget smartphone yang mampu memberikan akses yang cepat dan terpercaya. Sebagai sebuah kebutuhan dalam mendukung keberhasilan trading-nya perempuan membutuhkan alat bantu mesin, sehingga kolaborasi manusia dengan mesin digital sebagaimana pendefinisian cyborg terjadi pada diri perempuan.

Definisi konsep cyborg, menjadi pembahasan dalam pandangan cyberfeminist. Pemikiran Donna Harraway ini, menjadi kontroversi dari beberapa pandangan feminist terdahulunya yang justru menolak konsep tersebut dengan dalih berpihak pada pemilik modal. Keberadaan teknologi berbasis internet dianggap sebagai

\footnotetext{
12 berdasarkan penelitiannya (Ashari, Wibawa, \& Fad, 2017) terdapat 231 responden dari 6 Universitas di Kota Surabaya yang pernah berbelanja di online shop di Instagram.

${ }^{13}$ Diakses di http://www.temukanpengertian.com/2013/07/pengertian-informasi.html

${ }^{14}$ di akses di (https://kbbi.web.id/informasi)
} 
dominasi laki-laki terhadap perempuan dan menegaskan kepentingan pengusaha jaringan. Sementara itu, keberadaan informasi berbasis internet merupakan realitas yang tidak dapat dihindari kehadirannya. Oleh karena itu, upaya cyberfeminist menegaskan kembali konsep lama faham perempuan untuk melakukan perubahan dalam memahami konteks yang ada. Perempuan dan teknologi harus menjadi pemamahan baru bagi faham perempuan. Rekonstruksi ulang pemahaman terhadap perempuan dan teknologi harus dianggap sebagai peluang yang memberdayakan dan mensejajarkan perempuan dalam kehidupan sosialnya. Teknologi membantu perempuan dari keterbelakangan, percepatan pengolahan data informasi, efisiensi tenaga dan waktu dalam mengatasi pekerjaan domestiknya. Memang, kalau dilihat secara sekilas perempuan cyborg ini akan menjadi perempuan-perempuan yang sangat tangguh, dengan fakta sosial bahwa dalam dunia trader online yang mereka butuhkan adalah teknologi, seperti komputer ataupun laptop sebagai penunjang pekerjaanya. Mereka tidak perduli dengan laki-laki ataupun norma masyarakat yang berpihak kepadanya, sebab hal tersebut tidak akan mempengaruhi mereka sebagai seorang trader online. Maka kenapa mereka disebut sebagai perempuan cyborg.

Hal ini semacam seperti sebuah seni yang berpusat pada tokoh cyberfeminist yang juga mulai hidup di Internet. Seperti yang diharapkan, vagina dan klitoris memiliki kebanggaan dalam banyak pekerjaan cyberfeminis. Cyberfeminisme dapat menciptakan jaringan yang dirancang ulang di ranah maya, tubuh yang tergabung dalam karya tekstual, visual, dan interaktif. Secara simultan, proyek dekonstruksi yang membahas proliferasi kode budaya, gender, dan seksual yang dominan di Net akan lebih efektif jika berasal dari pusat libidinal yang kuat dan dipahami melalui filter sejarah perempuan dan teori feminis (Wilding, 1998).
Dalam menguasai informasi perempuan dapat menjadi cyborg, perempuan tidak membutuhkan laki-laki melainkan membutuhkan mesin yang canggih. Dalam menentukan kebenaran dan keakuratan informasi perempuan tidak membutuhkan norma masyarakat yang berpihak kepadanya, namun perempuan membutuhkan akses internet yang cepat tentunya mesin yang canggih yang dibutuhkan. Inilah yang dinamakan perempuan cyborg yang diperlukan perempuan dalam menguasai informasi.

Keinginan untuk membuktikan kemampuan para perempuan sebagai seorang cyberfeminism yang mampu hidup dan survive sendiri sangatlah tinggi, bahkan mereka akan terus berusaha untuk meningkatkan kelas mereka lebih setara daripada laki-laki. Dan menunjukkan kepada para laki-laki bahwa mereka juga bisa berkembang dan berjuang memenuhi kebutuhan mereka dalam hal ekonomi tanpa harus bergantung pada laki-laki. Hal ini juga terjadi pada studi yang dilakukan oleh (Akpinar, 2017), yang mana secara analisis gender, perempuan dengan penghasilan rendah sering mengalami perceraian dan kehidupannya berada di bawah dominasi patriarki. Begitu pula, (Chytkova \& Kjeldgaard, 2011) yang berpendapat bahwa perempuan dalam masyarakat kontemporer menggunakan sumber daya pasar online untuk membangun identitas individual dan ganda untuk mengurangi pengaruh patriarki dalam kehidupannya.

Cyberspace mampu menciptakan ruang belajar dan latihan terpisah dalam kelompok yang berbeda, dan tampaknya bermanfaat untuk memperluas dan mempertahankan ruang ini untuk sekarang dengan semangat bantuan diri feminis. Salah satu alat pendidikan paling penting yang bisa ditawarkan oleh para pelaku cyberfeminis adalah direktori strategi dan sumber daya elektronik yang terus berlanjut untuk wanita, termasuk kelompok diskusi teori feminis, tempat penerbitan dan pameran elektronik, zine, alamat, bibliografi, mediagraphies, situs how to, dan informasi umum. Meskipun, 
kompilasi beberapa sumber daya ini sudah ada, ada kebutuhan yang berkembang untuk wacana feminis yang lebih radikal dan kritis tentang teknologi di dunia maya.

Dalam cyberfeminisme, wacana ini muncul langsung dari praktik dan permasalahan aktual saat ini juga dari sebuah teori yang terbentuk (Wilding, 1998). Teknologi informasi membantu perempuan melampaui keterbatasan hidup yang dialaminya. Informasi bisa saja hanya sebagai berita, hanya teks, sebagai tulisan yang tidak memiliki makna karena tidak berarti apa-apa dan tidak tau bagaimana menggunakannya. Informasi pendidikan akan membatu bagi para pendidik dan dosen dalam pekerjaan, informasi kesehatan akan mebantu para dokter dan pasien dalam menangani kasusnya, begitu pula informasi tentang pasar saham akan membantu trader on-line dalam membangun keberhasilan tradingnya. Informasi pasar saham bagi yang mereka yang bukan trader saham tidak akan memiliki pengaruh apapun dan tidak berarti baginya, namun bagi trader on-line informasi tersebut mampu menjadi penentu keberhasilan dan kerugiannya. Meskipun secara teks materi dan preferensi fungsi sama, informasi hanya akan menjadi kalimat berita yang diabaikan begitu saja apabila tidak berguna bagi pembacanya. Pada nilai kebergunaan inilah sebuah informasi akan menjadi berharga dan membantu di penggunanya. Informasi pasar saham memiliki tingkat kebergunaan yang tinggi, maka informasi tersebut akan dicari berdasarkan tingkat kekuratannya dan dampaknya.

Pada titik inilah perempuan memerlukan teknologi informasi untuk mendayagunakan dirinya sebagai trader on-line. Informasi sebagai sumber utama dan rujukan sahih tentang pergerakan pasar saham, yang pada mulanya bersifat biasa saja sebagai penentu sebuah keberhasilan dan kerugian. Keberhasilan serta keuntungan trading akan diperoleh apabila informasi tersebut berdampak positif dan sinergi dengan arah pergerakan posisi saham yang ditradingkan sedangkan akan merugi apabila informasi yang ada cuma informasi hoaks, rumor dan tidak memberikan dampak yang signifikan dengan pergerakan saham yang diinginkan. Sebegitu besarnya pengaruh informasi bagi trader, maka perempuan harus memiliki alat bantu dan kemampuan yang tepat dalam memperoleh dan menganalisa informasi.

Beberapa informasi seperti informasi pembelian barang-barang murah, menentukan sasaran produk pada konsumen yang tersebar serta menentukan teknik pemasaran yang tepat. Selain itu penggunaan informasi juga untuk menentukan referensi konsep sehat dan sakit, perawatan serta pengobatan medis dengan beragam metode baik yang medis dan non-medis. Meskipun informasi diakui sulit dibedakan mana yang akurat dan berita hoaks atau rumor semata. seperti yang disampaikan oleh informan In dibawah ini:

"Agak sulit juga menentukan informasi yang benar di dunia seperti sekarang. Biasanya saya memnfaatkan web web yang sifatnya official dan sudah dikenal kredibilitasnya sebagai sumber informasi. Saya bergabung dalam komunitas jual beli online ini bertujuan untuk meningkatkan pemasukan karena selama ini gaji saya tidak cukup untuk memenuhi kebutuhan keluarga. Meskipun tidak ada keluarga yang mendukung saya, namun niat yang kuat dan tekad saya sudah bulat. Dengan komputer dan internet saya dapat menjual pada kota-kota yang jauh dengan mudah. Informasi antar sesama anggota cepat saya respon dan mencari tempat kulakan yang murah untuk saya jual dengan harga dibawah pasaran. ', (In, 2017).

Dari rekapan wawancara mendalam pada perempuan dalam komunitas jual beli online terlihat bahwa dunia informasi para perempuan begitu 
sangat penting, mereka tidak bisa hanya mengandalkan semuanya pada kondisi jual beli konvensional semata, karena kecepatan dan sasaran yang luas sangat kurang sehingga memerlukan mesin teknologi dan informasi. Perubahan kaum perempuan dalam memandang teknologi saat ini sudah jauh berbeda. Dalam hal ini, berbagai kondisi dan keadaan yang mengharuskan mereka untuk mempelajari teknologi dan informasi agar mereka tidak ketinggalan dengan laki-laki. Cara memandang kebermanfaatan teknologi pun beraneka ragam, tidak semua perempuan memberikan komentar positif namun sebagian memberikan pendapat negatif terkait informasi. Sebagian perempuan menggunakan teknologi membantunya sebagai mata pencarian, membuat kaum perempuan sangat ingin menguasai teknologi informasi dengan sebaik mungkin. Sebaliknya, sebagian perempuan lebih fokus pada cara mendapatkan ekonomi dengan jual beli on-line dibandingkan informasi yang cenderung tidak pasti dan hoaks yang berkaitan dengan dunia politik.

Cyberfeminisme dalam (Wilding, 1998), lebih menekankan pendekatan berbasis teknologi dalam mendukung kinerja perempuan dalam membangun komunitasnya melalui budaya menulis sebagai gerakan politisnya. Dengan menggunakan teknologi informasi yang berbasis pada kecepatan internet, maka gerakan perempuan ini akan meluas secara transnasional dan transkultural. Gerakan ini mampu mereduksi beberapa keadaan perempuan yang masih menggunakan konsep 'keterasingan' dalam medan budaya patriarkhi meskipun menggunakan komunikasi on-line yang ramah dalam menyuarakan haknya. Dengan konsep faham perempuan yang baru ini tentunya membuat nuansa gerakan perempuan menjadi berbeda, lebih kaya ide dan gagasannya, lebih kompleks, dan lebih produktif. Para pelaku on-line merasakan rasa kekeluargaan yang begitu erat meskipun disibukkan dengan kepentingan dan hal-hal lainnya. Dalam komunitas jual beli on-line ini berbeda, mereka menjadi pengguna aktif media internet untuk bekerja dan berjuang dalam memenuhi kebutuhan sosial ekonominya. Mereka juga membangun kepercayaan pada komunitas on-line-nya atas kemampuannya dalam penggunaan teknologi yang lebih produktif. Selain itu, mereka menemukan perasaan bersama dalam komunitas yang saling mendukung dan tetap survive berjuang bersama sebagai seorang pedagang on-line.

Para perempuan dalam komunitas on-line ini dapat disebut sebagai masyarakat jaringan, dimana sebuah masyarakat yang struktur sosialnya terbuat dari jaringan yang didukung oleh informasi mikroelektronika berbasis komunikasi-teknologi. Dengan struktur sosial, para perempuan ini memahami pengaturan organisasi manusia dalam hubungan produksi, konsumsi, reproduksi, pengalaman, dan kekuatan yang dinyatakan dalam komunikasi kode budaya. ${ }^{15}$ Untuk itu, perempuan yang menjalani kehidupan dalam masyarakat jaringan memiliki kemampuan dalam menggunakan teknologi internet tidak sekedar menggunakannya untuk konsumtif semata dan terjebak pada berita hoak yang tidak mampu membedakannya antara yang benar dan salah. Namun, baginya informasi mikroelektronika yang berbasis komunikasi-teknologi yang dianggap rumit tersebut dapat digunakan sebagai jual beli on-line untuk kepentingan pemberdayaan ekonomi, meningkatkan referensi sosial tentang nilai-nilai budaya yang universal yang lebih koheren dengan menghormati berbedaan.

Masyarakat jaringan merupakan sekumpulan masyarakat yang terhubung dengan masyarakat yang lainnya dan dipertemukan atas kepentingan yang sama, yaitu kepentingan jual beli on-line. Kemampuan masyarakat jaringan ini, khususnya

\footnotetext{
${ }^{15}$ Castells, 2004. The Network Society a Cross-cultural Perspective.
} 
para perempuan akan memberikan kontribusi bagi tujuan mereka dan juga bagi komunitas lainnya, karena mereka mampu memberikan pengaruh besar terhadap perkembangan kepada masyarakat lainnya yang tidak faham mengenai jual beli on-line. Selain itu, kemampuan jaringan yang mampu secara cepat merespon informasi dan menyebarluaskan ke pada khalayak ramai perlu diberikan apreasiasi, karena saat ini perempuan membutuhkan teknologi yang mampu membantu dan meringankan pekerjaannya dan diakui kemampuannya dalam jaringan informasi. Akan tetapi, ketersediaan teknologi masih harus menyesuaikan keadaan lingkungan dan juga kebutuhan perempuan yang ada disuatu yang berbeda kultur budaya, agar tidak menjadi hal yang sia-sia.

Pengorganisasian perempuan dalam komunitas jual beli on-line bukan hanya sekedar kegiatan jual beli dan berbagi informasi, menurut Castell kelompok ini akan mampu bertindak sebagai produsen sekaligus distributor bagi kode kultural. ${ }^{16}$ Adanya teknologi juga menjadi bagian dari perubahan kode budaya, baik itu secara individu maupun kelompok yang berinteraksi di dalamnya. Dalam kondisi saat ini, hampir semua perempuan muda memiliki jaringan mobile internet yang memudahkan dalam mengakses informasi, namun hanya sebagian saja yang mampu menikmati sebagai pengguna yang aktif, bermanfaat dalam meningkatkan status sosial ekonominya. Beberapa perubahan cara menghadapi realitas kehiduapan beserta gejala sosialnya, juga mempengaruhi pengguna aktif dalam sebaran jaringan teknologi informasi ini.

Menurut (Wheeler, 1981), pada abad milenial perempuan mengalami tiga tren pola perubahan dalam kehidupannya. Perubahan tren pola kehidupan pada perempuan tersebut meliputi: semakin meningkatnya umur harapan hidup, penurunan angka kelahiran serta meluasnya mobilitas pekerjaan bagi perempuan. Sedangkan, Castells mengungkapkan bahwa pada masyarakat informasional perempuan akan melakukan definisi ulang terhadap budaya patriarkhi. ${ }^{17}$ Temuan dari penelitian ini adalah perempuan dalam pemanfaatan teknologi informasi ini tidak menemukan adanya upaya perempuan untuk membangun koalisi hingga yang berujung pada keluarnya sebuah kebijakan. Sumber peluang yang minim bagi perempuan mengakibatkan perempuan bangkit menggunakan teknologi informasi dalam penjualan on-line. Upaya ini yang akhirnya mengubah tatanan sosial dengan beragam muncul sebagai perempuan yang aktif secara ekonomi dan mengubah tatanan patriarkhi.

Perempuan mengalami beragam perubahan, dominasi kelompok mayoritas mampu direduksi, kelompok marginal mampu menemukan identitasnya dan peran negara dapat diabaikan. Selain itu, temuan baru yang tidak relevan dengan konsepnya Castells, yang menganggap era informasi membuat perempuan akan bergerilya membentuk kelompok identitasnya yang baru seiring arus globalisasi, seperti halnya gerakan fundamentalis agama. ${ }^{18}$ Namun, pada penelitian ini penggunaan informasi digunakan untuk mendapatkan keuntungan ekonomi sosial. Artinya kemampuan bertahan dipengaruhi oleh informasi yang didapat terakurasi dengan tepat atau tidak. Informasi bukan sebagai referensi membentuk identitas diri melainkan sebagai referensi pencapaian ketahanan hidup secara ekonomi.

Adanya teknologi juga menjadi bagian dari perubahan sosial, baik itu secara struktur ataupun

\footnotetext{
${ }^{16}$ Manuel Castells.1997. The Information Age: Economy, Society, and Culture Volume II. The Power of Identity. Second Edition. With A New Preface. Wiley-Blackwell Publication.

${ }^{17}$ Ibid....

${ }^{18}$ Manuel Castells.1997. The Information Age: Economy, Society, and Culture Volume II. The Power of Identity. Second Edition. With A New Preface. Wiley-Blackwell Publication
} 
interaksi yang ada di dalamnya, karena teknologi adalah suatu hal yang juga langkah yang dimiliki oleh setiap orang, meskipun hanya sebagian orang yang mampu menikmati teknologi sebagai sumber informasi saat ini. Perubahan-perubahan yang terjadi adalah gaya hidup dengan cara pandangnya sendiri terhadap gejala sosial di lingkunganya, karena hal tersebut diperoleh melalui informasi yang telah tersebar pada jaringan teknologi informasi. Dari hasil penelitian didapatkan bahwa beberapa yang menggunakan informasi sebagai penentu keberhasilan perdagangannya meskipun sulit menentukan informasi tersebut benar-benar valid atau tidak dalam mempengaruhi perdagangannya. Informasi juga berkaitan dengan analisa pasar dalam memperkirakan arah konsumen dalam menentukan permintaan serta daerah yang tepat sasaran produk. Selain itu, kondisi persaingan antar pedagang juga menentukan harga produk disamping kualitas barang yang dijual. Beberapa perempuan memberikan pernyataan bahwa tidak semua web media internet memberikan informasi yang valid, sehingga lebih percaya pada beberapa web yang digunakan oleh pedangang yang lebih senior dan berpengalaman dalam komunitas untuk menentukan web mana yang dapat di percaya dalam memberikan informasi.

\section{KESIMPULAN}

Perubahan sosial terjadi sebagai upaya dalam merespon realitas hadirnya teknologi informasi. Dengan kata lain, perempuan juga berubah dalam menanggapinya dengan mengubah persepsi umum tentang perempuan yang gaptek ${ }^{19}$ dan menjadi penonton saja. Perempuan memacu diri dalam meningkatkan kesadaran pentingnya menempati ruang pengetahuan dan ketrampilan teknologi informasi. Upaya perempuan berkoordinasi dengan teknologi untuk mencari dan mendapatkan profesi yang lebih luas. Sebuah profesi yang lebih kondusif bagi perempuan dalam merepresentasikan diri, sekaligus sebagai tempat bersembunyi dari struktur tradisi dan kepercayaan. Biarpun demikian, perempuan masih sedikit yang memanfaatkannya, mereka masih terjebak sebagai pengguna pasif ketimbang sebagai pelaku aktif.

Cyberfeminist sebagai gerakan perempuan dalam penggunaan media teknologi informasi untuk membangun koalisi bersama dalam mewujudkan kebijakan yang menghargai keberadaan perempuan. Upaya ini mendorong para perempuan di dunia menjadi bagian dari teknologi informasi baik sebagai pencipta atau sebagai pengguna aktif yang memberdayakannya. Para perempuan dalam gerakan ini meyakini bahwasanya teknologi informasi mampu mengubah perempuan lebih berdaya dan setara dengan laki-laki, serta mampu mengatasi kompleksitas kondisi sosial yang ada. Akan tetapi, apa yang terjadi pada hasil penelitian ini menunjukkan bahwa perempuan yang menggunakan teknologi informasi secara aktif ini tidak berupaya untuk membangun koalisi yang bertujuan pada kebijakan yang resposif pada perempuan. Perempuan-perempuan yang aktif dalam jual beli on-line ini justru mampu menunjukkan keberadaan meskipun tanpa melalui alur kebijakan. Ia terbebas dalam upaya mendapatkan dukungan kebijakan yang berpihak padanya, artinya negara tidak diperlukan dalam mendukung kegiatannya tersebut. Perempuan ini lebih memilih untuk fokus pada bagaimana meningkatkan kemampuannya dalam menguasai teknologi informasi ketimbang berkutat pada sektor lembaga yang mendukungnya. Baginya kemandirian terlepas dari lembaga apapun lebih diutamakan, ketimbang melakukan gerakan sebagaimana kaum cyberfeminist melakukan

\footnotetext{
${ }^{19}$ gaptek adalah istilah untuk seseorang yang awam terhadap teknologi atau biasa dengan sebutan gagap teknologi.
} 
gerakan menulis dalam komunitas on-line untuk mendorong kebijakan yang berpihak padanya.

Saran dari penelitian selanjutnya ada pada ketersediaan fasilitas bagi perempuan dalam penggunaan media on-line secara aktif dan produktif. Selain itu, penelitian lainnya dapat menekankan pada aspek hambatan kegagalan perempuan dalam menggunakan teknologi. Penelitian ini hanya fokus pada perempuan yang berhasil, belum menyentuh pada moral hazard dari teknologi informasi. Sebenarnya, banyak sekali kesalahan-kesalahan produksi informasi yang menimbulkan kebingungan, persepsi yang membuat perempuan tidak mampu mencernanya sehingga terjebak pada ketidakberdayaannya. Contohnya, konsumerisme diproduksi oleh teknologi informasi, struktur dominasi kultur yang mematikan kesadaran perempuan, ideologi politik yang nampak natural sehingga ia terjebak pada informasi palsu yang menyebabkan kerugian.

\section{DAFTAR PUSTAKA}

Wilding, F. (1998). Critical Art Ensemble, Notes on the Political Condition of Cyberfeminism,. 57, 46-59.

Hilbert, Martin. 2011. Digital gender divide or technologically empowered women in developing countries? (A typical case of lies, damned lies, and statistics), (University of Southern California (USC); United Nations Economic Commission for Latin America and the Caribbean (ECLAC/CEPAL). hlm. 1-2. Hafkin, Nancy., Taggart, Nancy. 2000. Gender, Information Technology, and Developing Countries: An Analytic Study, (Academy for Educational Development (AED) For the Office of Women in Development Bureau for Global Programs, Field Support and Research United States Agency for International Development. hlm. 3-4.

Castells, Manuel. 1997. The Information Age: Economy, Society, and Culture Volume II. The Power of Identity. Second Edition. With-
A New Preface. Wiley-Blackwell Publication. Web : http://www.temukanpengertian.com/2013/ 07/pengertian-informasi.html yang diakses pada 20 Mei 2018.

Web : (https://kbbi.web.id/informasi) yang di akses pada 20 Mei 2018.

Wilding, F. (1998). Critical Art Ensemble, Notes on the Political Condition of Cyberfeminism, 57, 46-59.

Fernande, M. (2003). Cyberfeminism, Racism, Embodiment.

Fernandez, M., \& Wilding, F. (2002). Situating Cyberfeminisms. Domain errors: Cyberfeminist practices.

Sitokdana, M. N. (2015). Evaluasi Implementasi eGovernment Pada Situs Web Pemerintah Kota Surabaya, Medan, Banjarmasin, Makassar dan Jayapura. VI (4).

Fauzia, I. Y. (2015). Pemanfaatan e-commerce dan m-commerce dalam bisnis di kalangan wirausahawan perempuan. Journal of Bisnis and Banking , 5 (6).

Aryaningsih, D. (2011). (Universitas Airlangga Surabaya) Retrieved 2 20, 2018, from http://repository.unair.ac.id/id/eprint/17327

Novandra, A. S. (2017). (Universitas Airlangga Surabaya) Retrieved 2 20, 2018, from http://repository.unair.ac.id/id/eprint/59157

Ashari, B. H., Wibawa, M. B., \& Fad, S. (2017). Analisis Deskriptif dan Tabulasi Silang pada Konsumen Online shop di Instagram (Studi Kasus 6 Universitas di Kota Surabaya). SAINS and SENI ITS , 6.

Volkart, Y. (2004). The Cyberfeminist Fantasy of the Pleasure of the Cyborg 1). (C. Reiche, \& K. Verena, Eds.) Cyberfeminism. Next Protocols .

Wheeler, H. (1981). The Middle-Aged "Older Woman": A Feminist Librarian's Approach to Library Resources. Collection Building, 3 (1), 19-30.

Akpinar, A. (2017). Turkish Divorcées and Need for Woman-friendly Policies. (G. Tibe Bonifacio, Ed.) $93-105$.

Chytkova, Z., \& Kjeldgaard, D. (2011). The Modern Woman Myth as a means of Cosmopolitan Cultural Capital Accumulation: A Gendered Acculturation Perspective. (R. W. Belk, K. Grayson, A. M. Muñiz, \& H. Jensen Schau, Eds.) Research in Consumer Behavior, 13, 199-216. 